\title{
Caribbean free-living coral species co-occurring deep off the windward coast of Curaçao
}

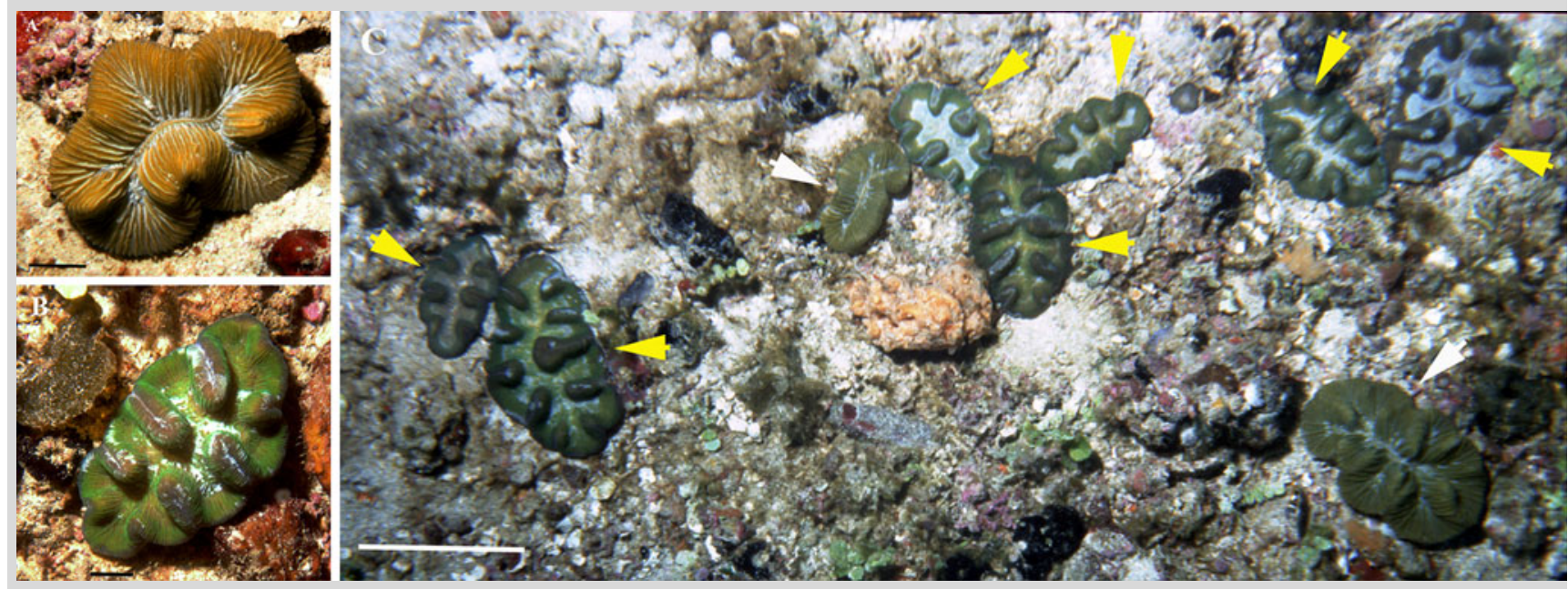

Fig. 1 Free-living corals off Curaçao. a Meandrina danae. b Manicina aerolata. c Area with high coral densities (white arrows M. danae, yellow arrows M. aerolata). Depth $=40-45 \mathrm{~m}$. Scale bars a, b $1 \mathrm{~cm}, \mathbf{c} 5 \mathrm{~cm}$

We document the co-occurrence of two Caribbean species of free-living zooxanthellate corals, Meandrina danae (Milne-Edwards and Haime 1848) (Fig. 1a) and Manicina areolata (Linnaeus 1758) (Fig. 1b), in a previously not well-documented environment. The two species were encountered at three locations (ranging from 30 to $50 \mathrm{~m}$ depth) on the windward side of the island of Curaçao, southern Caribbean. Corals are present beyond the reef base on substrate consisting of coarse coral sand, small rubble, and fragments of shells and calcareous algae (Fig. 1c). Colony sizes (mean length) were 58 mm (SD 18, $n=133$ ) for M. areolata and $67 \mathrm{~mm}(\mathrm{SD} 19, n=32)$ for $M$. danae. Maximum colony density of both species together was 30 individuals per $\mathrm{m}^{2}$ with $M$. areolata colonies being 9 times as abundant.

None of these species has been reported from such a deep habitat. $M$. danae has never previously been recorded on the island while $M$. areolata has been described in shallow sandy areas in Curaçao by Roos (1971). It was reported in seagrass beds and on sandy and rubble areas on the reef down to $20 \mathrm{~m}$ in Jamaica (Goreau and Goreau 1960) and in seagrass flats and mangrove-associated communities in the San Blas Archipelago, northern Panama (Johnson 1992). Furthermore, free-living scleractinian corals can form dense and species-rich assemblages on sandy habitats of Indo-Pacific reef systems (Hoeksema 2012). To our knowledge, this is the first documented multi-species assemblage of free-living zooxanthellate corals in the Caribbean.

Acknowledgments E.H.M. thanks Ineke Wesseling for her enthusiastic support.

\section{References}

Goreau TF, Goreau NI (1960) Distribution of labeled carbon in reef-building corals with and without zooxanthellae. Science 131:668-669 Hoeksema BW (2012) Distribution patterns of mushroom corals (Scleractinia: Fungiidae) across the Spermonde Shelf, South Sulawesi. Raffles Bull Zool 60:183-212

Johnson KG (1992) Population dynamics of a free-living coral: Recruitment, growth and survivorship of Manicina areolata (Linnaeus) on the Caribbean coast of Panama. J Exp Mar Biol Ecol 164:171-191

Roos PJ (1971) The shallow-water stony corals of the Netherlands Antilles. Stud Fauna Curaçao 130:1-108

\section{E. H. Meesters $(\square)$}

Institute for Marine Resources and Ecosystem Studies (IMARES), Wageningen University, PO Box 167, 1790 AD Den Burg, Texel, The Netherlands e-mail: Erik.Meesters@wur.nl

B. Mueller

Royal Netherlands Institute for Sea Research, PO Box 59, 1790 AB Den Burg, The Netherlands

M. M. Nugues

Laboratoire d'Excellence 'CORAIL' and USR 3278 CRIOBE CNRS-EPHE, 66860 Perpignan Cedex, France

Received: 4 July 2012/Accepted: 18 September 2012/Published online: 9 October 2012

Coral Reefs (2013) 32:109

(C) Springer-Verlag Berlin Heidelberg 2012

DOI 10.1007/s00338-012-0960-6 